\title{
HDL-Bound Sphingosine 1-Phosphate (S1P) Predicts the Severity of Coronary Artery Atherosclerosis
}

\author{
Katherine Sattler ${ }^{\mathrm{a}}$ Isa Lehmann ${ }^{\mathrm{a}}$ Markus Gräler ${ }^{\mathrm{b}}$ Martina Bröcker-Preuss ${ }^{\mathrm{c}}$ \\ Raimund Erbeld Gerd Heusch ${ }^{a}$ Bodo Levkau ${ }^{a}$ \\ Institute for Pathophysiology, University Duisburg-Essen, Essen, ${ }^{\mathrm{b} C l i n i c}$ for Anesthesiology and \\ Intensive Care Medicine, SG Sepsis Research, Center for Molecular Biomedicine, University Hospital \\ Jena, 'Department of Clinical Chemistry, University Duisburg-Essen, Essen, ${ }^{\mathrm{d} C l i n i c}$ for Cardiology, West \\ German Heart Center, University Duisburg-Essen, Essen, Germany
}

\section{Key Words}

Sphingosine 1-phosphate (S1P) - High-density lipoproteins (HDL) - Stable coronary artery disease $(C A D) \cdot$ Stenosis $・$ Restenosis $•$ Multi-vessel disease

\begin{abstract}
Background: We have recently demonstrated a reduction in HDL-bound sphingosine 1-phosphate (S1P) in patients with stable coronary artery disease (CAD). In the current study, we tested whether HDL-associated S1P is predictive for the degree of coronary stenosis, restenosis and overall CAD severity on follow up in patients undergoing elective percutaneous coronary intervention (PCI). Methods: Coronary angiography of patients with CAD $(n=59)$ undergoing elective PCI and presenting for a follow up after 6 months $(n=48)$ was graded for disease severity defined clinically as 1- or multi-vessel disease. Target lesion stenosis was quantified by quantitative coronary angiography (QCA). S1P in plasma and isolated HDL were measured by mass spectrometry in the initial samples and in 32 available follow up samples. Results: HDL-bound S1P levels remained stable over time and correlated closely at first visit and follow up. While not associated with the extent of target lesion stenosis or restenosis, HDL-bound S1P correlated negatively with the overall severity of CAD and discriminated 1 -vessel-disease from multi-vessel disease. Furthermore, low HDL-bound S1P was predictive for CAD extent. Conclusion: In stable CAD, HDL-bound S1P does not predict the degree of stenosis or restenosis of the target lesion but constitutes a marker of clinically defined disease burden.
\end{abstract}

Copyright (C) 2014 S. Karger AG, Basel

Prof. Dr. Bodo Levkau 
Sattler et al.: HDL-S1P Predicts Plaque Burden

\section{Introduction}

Coronary artery disease (CAD) is the clinical manifestation of atherosclerosis of the coronary artery vascular bed. The disease eventually leads to acute coronary syndromes and ischemic heart disease, and caused $13.3 \%$ of all deaths worldwide in 2010 [1]. Among all risk factors for CAD, dyslipidemia plays a crucial role. Its hallmarks are elevated plasma levels of low density-lipoprotein cholesterol (LDL-C) and decreased levels of high densitylipoprotein cholesterol (HDL-C). In fact, plasma HDL-C levels are known as epidemiologically negative predictors of CAD $[2,3]$. Mechanistically, the main anti-atherogenic function of HDL is the reverse cholesterol transport from peripheral tissues to the liver for excretion with the bile [4]. However, several other potentially atheroprotective mechanisms of HDL have been discussed [5]. As HDL are complex particles composed of dozens of proteins and hundreds of different lipids, much attention has been given to the molecular entities inside HDL that mediate individual biological effects. We and others have identified the biologically active sphingolipid sphingosine 1-phosphate (S1P) that is contained in HDL to be responsible for several of their potentially vaso- and cardioprotective functions [6-11]. Recently, we have demonstrated that the plasma S1P levels are elevated and that its distribution shifted from HDL towards non-HDL-carriers in stable CAD and acute myocardial infarction [12]. Earlier, total serum S1P has been identified as a predictor of the presence of CAD and the severity of coronary artery stenosis [13].

In the current study, we have tested whether HDL-bound plasma S1P was predictive of CAD extent or stenosis severity of the coronary arteries in a cohort of patients undergoing elective percutaneous coronary intervention (PCI). Our results demonstrate that the S1P distribution between HDL and other carriers was able to discriminate patients according to the extent of the underlying disease and to predict disease extent. Nevertheless, there was no association with the severity of stenosis and restenosis. We also performed measurements of S1P on follow-up, allowing for the first time the monitoring of S1P distribution in plasma in CAD over time.

\section{Materials and Methods}

\section{Study participants}

From 2006 to 2007, consecutive patients presenting with stable coronary artery disease (CAD) for elective percutaneous coronary intervention (PCI) at the Clinic of Cardiology, West German Heart Center, University Hospital Essen, were invited to participate in the study on the day before PCI procedure. Patients were included in the study if they were $>18$ years of age and had stable cardiac symptoms over the last 6 months. Exclusion criteria were unstable angina pectoris and renal insufficiency (calculated GFR $<60 \mathrm{ml} /$ $\mathrm{min} / 1,73 \mathrm{~m}^{2}$ ). Written informed consent was obtained from all participants. The study was approved by the local ethics committee (protocol no. 06-2965).

\section{Follow up}

In case a participant visited the Clinic of Cardiology after the initial visit again either as an outpatient or for invasive coronary artery treatment, this visit was considered the "follow up visit" of the respective participant. Time to re-visit was taken as "time to follow up". A blood sample was collected during this visit either during outpatient stay or on the morning following PCI if another PCI was performed, and was classified "follow up sample".

\section{Blood sampling and processing}

Blood was drawn from a peripheral vein into vacuum tubes containing $1.6 \mathrm{mg}$ EDTA/mL to prevent clot formation during a routine blood sampling on the morning following PCI. Plasma was generated by centrifugation and frozen at $-80^{\circ} \mathrm{C}$ until further processing. High density- lipoproteins (HDL) were isolated 
Sattler et al.: HDL-S1P Predicts Plaque Burden

by sequential density gradient ultracentrifugation according to their density of $1.069-1.21 \mathrm{~g} / \mathrm{mL}$, following an established protocol [12]. In plasma and in isolated HDL, the levels of HDL-cholesterol (HDL-C) and cholesterol, respectively, were determined in the central laboratory of the University Hospital Essen (cholesterol: Advia Chemistry Systems, coefficient of variance (CV) 1.45\%, HDL-C: Advia Chemistry Systems DHDL, CV 2.36\%, Bayer Health Care, Germany). Sphingosine 1-phosphate (S1P) was determined in plasma and in isolated HDL by LCMS as described [12].

\section{Parameters of S1P distribution in plasma}

From the parameters measured (HDL-C and S1P in plasma; cholesterol and S1P in isolated HDL), we calculated several derived parameters as described previously [12]: HDL-bound plasma S1P [pmol/mL], non-HDL-bound plasma S1P [pmol/mL], fraction of HDL-bound plasma S1P, fraction of non-HDL-bound plasma S1P, HDL-C normalized HDL-bound plasma S1P [pmol/mg HDL-C], and the proportion of non-HDLbound plasma S1P to HDL-C normalized HDL-bound plasma $[\mathrm{mg} / \mathrm{mL}]$.

\section{Percutaneous coronary intervention and severity of coronary artery disease}

Patients were classified as having 1-, 2- or 3-vessel disease by the investigator performing the PCI procedure. A coronary artery was termed diseased if a previous coronary intervention (PCI or bypass surgery) had been performed in this vessel or if plaques were visible on the angiograms taken during PCI. Quantitative coronary angiography (QCA, QCA-CMS 5.0, MEDIS, The Netherlands) of the target lesion was performed on angiograms taken prior to and after angioplasty and, if applicable, during a follow up visit. For quantification of lesion severity, the angiogram presenting the most severe presentation of the lesion prior to intervention was chosen. For subsequent analyses, angiograms showing the same view were used. The reference vessel diameter [mm], the minimal luminal diameter [mm], the percent diameter stenosis [\%] and the stenosis area [\%] of the target lesions were recorded prior to and after angioplasty. The same parameters of the target lesion were obtained on the angiograms taken during follow up visit. Lumen loss at follow up [mm] was defined as the difference of the minimal luminal diameter after the intervention and the minimal luminal diameter at follow up. The percent diameter restenosis [\%] was the difference of the percent diameter stenosis after the intervention and the percent diameter stenosis at follow up. Binary restenosis rate was defined as the rate of percent diameter restenosis $\geq 50 \%$ [14].

\section{Data management}

Patients' data of risk factors and laboratory values of the initial visit and the follow up visit were collected from the hospital's patients recording system. Percutaneous coronary interventions, QCA analyses, collection and analysis of patients' data and all experimental procedures were performed by investigators blinded to the results of the S1P measurements.

\section{Statistics}

Data are expressed by median (minimum - maximum) for continuous variables and frequency count and percentage for qualitative variables. As most of the S1P-related parameters with the exception of plasma S1P and HDL-C normalized HDL-bound plasma S1P were non-normally distributed (data not shown), MannWhitney-rank-sum test for non-parametric data was used for the comparison of groups. Spearman's rankorder correlation was used to test for any association of variables. The results of the tests for association are presented as correlation coefficient $r$ and the $\mathrm{P}$ value. Receiver-operating characteristic (ROC) curves (assuming non-parametric distribution) were calculated for each S1P-related parameter to evaluate its ability to categorize patients into groups with different grades of CAD severity. The results presented are the areas under the curve, the standard error of the mean, the $\mathrm{P}$ values and the $95 \%$ confidence interval. S1P parameters positive for discriminating CAD grades in the ROC analysis $(A U C \geq 0.70, P<0.05$ ) were dichotomized at the cut-off levels calculated by Youden index. The dichotomized variables were then entered into a logistic regression analysis to predict the dependent variable "severity of coronary obstruction" on the basis of the cut-off levels. P-values are understood to be strictly descriptive. Statistical significance was assumed for $\mathrm{P}<0.05$. All analyses and graphs were performed with SPSS 18.0. 


\section{Results}

\section{Study population}

The patient group consisted of 59 patients (14 female (24\%) and 45 male (76\%)). Median age was 65 years. Fifty three patients (90\%) suffered from known coronary artery disease (CAD), and 16 patients (27\%) had a history of coronary bypass surgery. The patients' demographic and clinical data are presented in Table 1.

S1P levels in plasma, isolated HDL and associated with the HDL fraction in plasma

Total plasma sphingosine 1-phosphate (S1P) of all patients was $245 \mathrm{pmol} / \mathrm{mL}$ (Table 2 ). The S1P content of high density-lipoproteins (HDL) isolated from the same plasma was $455 \mathrm{pmol} / \mathrm{mg}$ cholesterol and $117 \mathrm{pmol} / \mathrm{mg}$ protein (Table 2 ), confirming values obtained by us in patients with CAD in a preceding study [12]. In further agreement, the majority of plasma S1P was associated with plasma HDL-cholesterol (HDL-C; 92\%). To account for different plasma HDL-C concentrations, absolute values for HDL-associated plasma S1P (215pmol/ $\mathrm{mL}$ plasma) were normalized to HDL-C levels, resulting in $451 \mathrm{pmol} / \mathrm{mg}$ of plasma HDL-C. In comparison, S1P not associated with HDL was low $(14 \mathrm{pmol} / \mathrm{mL})$. The plasma levels of HDL-C were closely correlated to the levels of HDL-bound plasma S1P $(r=0.51, \mathrm{P}<0.01)$ as well as to the fraction of HDL-bound plasma S1P $(\mathrm{r}=0.27, \mathrm{P}=0.04)$. The S1P content in isolated HDL (117 pmol/mg protein) was positively correlated to total plasma S1P levels $(\mathrm{r}=0.3, \mathrm{P}=0.02)$. All parameters are shown in detail in Table 2.

Extent of coronary artery disease and characteristics of coronary intervention procedure Of the study patients, 16 (27\%) had a 1-vessel-disease, 15 (25\%) had a 2-vessel-disease, and $28(47 \%)$ had a 3 -vessel-disease. The latter two patient groups were defined as group with multi-vessel disease $(n=43,73 \%)$. During the percutaneous coronary intervention procedure (PCI), 67 lesions were identified and treated by implantation of 88 stents. The distribution of target lesions within the coronary system is shown in table 1 . During the procedure, pre-dilation was performed in 22 (37\%) patients, post-dilation in $13(22 \%)$ patients, intravascular ultrasound in 18 (32\%) patients prior to and in $23(40 \%)$ patients post PCI. There was no association of any S1P-related parameters with cardiac Troponin I (cTnI) before or 12 hours after PCI $(0.01 \mathrm{ng} / \mathrm{mL}(0.00-0.08)$ and $0.05 \mathrm{ng} / \mathrm{mL}(0.00-2.92)$, respectively) excluding PCI related [15] or ischemia-related [12] changes of plasma S1P.

No association between stenosis of the individual target lesion and the S1P content of plasma or $H D L$

The initial coronary angiography revealed total coronary artery occlusion in three cases, while all other target lesions were coronary artery stenoses. The detailed results of the quantitative coronary angiography (QCA) of the target lesions are shown in Table 3. To test for an association between luminal obstruction and S1P-related parameters, we correlated each of them with the QCA results of the target lesion. Neither the S1P content in HDL nor any of the other S1P-related parameters were associated with the QCA measurements of the target lesion (data not shown).

Negative association of overall CAD severity (defined as 1-vessel disease compared to multi-vessel disease) and the levels of HDL-bound plasma S1P

Previously, serum S1P levels have been reported to be predictive for a coronary obstruction score defined by Deutschman et al. [13]. We tested whether any of the S1Prelated parameters including plasma S1P were predictive for overall CAD severity that was defined as the clinically used classification of 1-vessel disease (1-VD, plaques angiographically detected in only one coronary artery disease) or multi-vessel disease (multi-VD, plaques angiographically detected in 2 or 3 coronary arteries).

Total plasma S1P was comparable among both CAD groups (1-VD: $225 \mathrm{pmol} / \mathrm{mL}$, multiVD: $230 \mathrm{pmol} / \mathrm{mL}$; Table 4). However, patients with multi-VD had lower HDL-bound plasma 
Sattler et al.: HDL-S1P Predicts Plaque Burden

Table 1. Demographical and clinical data of the study population at the time of percutaneous coronary intervention. CABG - coronary artery bypass graft. CAD - coronary artery disease. CCS - Canadian Cardiovascular Score. Note: CCS-classification was available for 58 patients only, thus CCS data are given as the number of positive observations and the percentage of total recorded counts of observation. Continuous variables are presented as median (minimum - maximum), qualitative variables are given as number and percentage

\begin{tabular}{lc}
\hline & $\begin{array}{c}\text { Plasma levels or frequency } \\
(\mathrm{n}=59)\end{array}$ \\
\hline Total cholesterol $[\mathrm{mg} / \mathrm{mL}]$ & $1.71(0.90-2.89)$ \\
High density-lipoprotein-cholesterol $[\mathrm{mg} / \mathrm{mL}]$ & $0.45(0.25-0.78)$ \\
Low density-lipoprotein-cholesterol $[\mathrm{mg} / \mathrm{mL}]$ & $0.91(0.35-1.90)$ \\
Body mass index $\left[\mathrm{kg} / \mathrm{m}^{2}\right]$ & $27(15-45)$ \\
Arterial hypertension $[\mathrm{n}, \%]$ & $58(98)$ \\
Hypercholesterolemia [n, \%] & $55(93)$ \\
Hypertriglyceridemia [n, \%] & $12(20)$ \\
Elevated lipoprotein $(\mathrm{a})[\mathrm{n}, \%]$ & $20(36)$ \\
Hyperhomocysteinemia [n, \%] & $17(36)$ \\
Diabetes mellitus [n, \%] & $12(20)$ \\
Current smoker [n, \%] & $8(14)$ \\
Severity of symptoms [n, \%] & \\
- CCS I & $13(22)$ \\
- CCS II & $32(55)$ \\
- CCS III & $10(17)$ \\
- CCS IV & $3(5)$ \\
Previous CABG [n, \%] & $16(27)$ \\
Newly diagnosed CAD [n, \%] & $6(10)$ \\
Localization of target lesion [n, \%] & \\
- Left anterior descending & $34(50.7)$ \\
- Ramus circumflexus & $14(20.9)$ \\
- Right coronary artery & $15(22.4)$ \\
- Saphenous vein graft & $2(2.9)$ \\
- Ramus diagonalis 1 & $1(1.5)$ \\
- Ramus interventricularis posterior & $1(1.5)$ \\
\hline
\end{tabular}

Table 2. Levels of sphingosine 1-phosphate in high density-lipoproteins and in plasma at first visit and follow up. HDL - high density-lipoproteins, HDL-C - high density-lipoprotein cholesterol, S1P - sphingosine 1-phosphate. Plasma was generated from peripheral venous blood drawn 12 hours after PCI at index intervention or at follow up, and HDL were isolated. HDL-C, S1P, and HDL-cholesterol were determined as described. Data are shown as median (minimum - maximum). ${ }^{*} \mathrm{P}<0.01$ vs. levels at first visit

\begin{tabular}{lccc}
\hline & $\begin{array}{c}\text { Levels at first visit } \\
\text { (n=59) }\end{array}$ & $\begin{array}{c}\text { Levels at first visit of patients with } \\
\text { measurements at follow up } \\
(\mathrm{n}=32)\end{array}$ & $\begin{array}{c}\text { Levels at follow up } \\
\text { (n=32) }\end{array}$ \\
\hline S1P in HDL/cholesterol in HDL [pmol/mg] & $455(62-1883)$ & $481(62-871)$ & $468(62-917)$ \\
S1P in HDL/protein in HDL [pmol/mg] & $117(20-292)$ & $126(20-254)$ & $153(22-289)$ \\
Total plasma S1P [pmol/mL] & $245(85-545)$ & $275(85-445)$ & $308(110-640)$ \\
HDL-bound plasma S1P [pmol/mL] & $215(25-1149)$ & $226(25-609)$ & $228(27-555)$ \\
Non-HDL-bound plasma S1P [pmol/mL] & $14(-929-265)$ & $38(-259-265)$ & $45(-437-307)$ \\
Fraction of non-HDL-bound plasma S1P & $0.07(-4.2-0.9)$ & $0.1(-0.7-0.9)$ & $0.2(-0.5-0.9)^{*}$ \\
Fraction of HDL-bound plasma S1P & $0.9(0.1-5.2)$ & $0.9(0.1-1.7)$ & $0.8(0.1-1.5)^{*}$ \\
HDL-C normalized HDL-bound plasma S1P [pmol/mg] & $451(62-1883)$ & $481(62-871)$ & $460(62-917)$ \\
Non-HDL-bound plasma S1P:HDL-C normalized HDL-bound plasma S1P [mg/mL] & $0.03(-0.5-4.3)$ & $0.07(-0.3-4.3)$ & $0.11(-1.0-3.7)$ \\
Plasma HDL-C [mg/mL] & $0.45(0.25-0.78)$ & $0.47(0.25-0.78)$ & $0.44(0.25-0.83)$ \\
\hline
\end{tabular}

Table 3. QCA measurements of the target lesions before and after percutaneous coronary intervention at the first visit and at follow up. PCI - percutaneous coronary intervention, QCA - quantitative coronary angiography. The definition of the QCA parameters is given in the methodology section. Data are shown as median (minimum - maximum). ${ }^{*} \mathrm{P}<0.01$ vs. results after $\mathrm{PCI}$ at first visit

\begin{tabular}{lcccc}
\hline & $\begin{array}{c}\text { First visit, prior to PCI } \\
(\mathrm{n}=67 \text { target lesions) }\end{array}$ & $\begin{array}{c}\text { First visit, after PCI } \\
(\mathrm{n}=67 \text { target lesions) }\end{array}$ & $\begin{array}{c}\text { First visit, after PCI, } \\
\text { patients with measurements at follow up } \\
(\mathrm{n}=52 \text { target lesions) }\end{array}$ & $\begin{array}{c}\text { Follow up } \\
\text { (n=52 target lesions) }\end{array}$ \\
\hline Minimal lumen diameter [mm] & $1.21(0.50-2.31)$ & $2.69(1.45-4.00)$ & $2.63(1.45-4.00)$ & $2.29(0.08-3.78) *$ \\
Diameter stenosis [\%] & $57.32(32.56-100.00)$ & $15.00(5.10-33.80)$ & $16.19(6.72-33.80)$ & $24.08(5.40-70.90) *$ \\
Stenosis area [\%] & $81.72(54.46-100.00)$ & $27.72(9.96-56.08)$ & $29.74(12.96-56.08)$ & $42.35(10.50-91.50) *$ \\
Reference diameter [mm] & $2.95(2.00-4.00)$ & $3.24(2.16-4.49)$ & $3.19(2.16-4.49)$ & $2.93(2.04-4.41)$ \\
Lumen loss [mm] & - & - & - & - \\
Diameter of restenosis [\%] & - & - & - & $3.32(-1.09-2.96)$ \\
\hline
\end{tabular}

S1P (194pmol/mL) than patients with 1-VD (248pmol/mL, P<0.05; Fig. 1). Accordingly, they had higher non-HDL-bound plasma S1P levels (41 pmol/mL) than patients with 1-VD (27 pmol/mL, P<0.05). 
Table 4. S1P-related parameters in patients with 1-vessel disease or multi-vessel (2-vessel- or 3-vessel) -disease. HDL - high density-lipoproteins, HDL-C - high density-lipoprotein cholesterol, S1P - sphingosine 1-phosphate. Plasma was generated from peripheral venous blood drawn 12 hours after PCI, and HDL were isolated. HDL-C, S1P, and HDL-cholesterol were determined as described. Data are shown as median (minimum - maximum). * $\mathrm{P}<0.05$ vs. 1 -vessel disease

\begin{tabular}{lcc}
\hline & $\begin{array}{c}\text { 1-vessel disease } \\
(\mathrm{n}=16)\end{array}$ & $\begin{array}{c}\text { multi-vessel disease } \\
(\mathrm{n}=43)\end{array}$ \\
\hline S1P in HDL/cholesterol in HDL [pmol/mg] & $534(308-811)$ & $420(62-1883)$ \\
S1P in HDL/protein in HDL [pmol/mg] & $131(72-254)$ & $110(20-292)$ \\
Total plasma S1P [pmol/mL] & $225(180-350)$ & $230(85-395)$ \\
HDL-bound plasma S1P [pmol/mL] & $248(108-609)$ & $194(25-1149)^{*}$ \\
Non-HDL-bound plasma S1P [pmol/mL] & $-27(-259-207)$ & $41(-929-265)^{*}$ \\
Fraction of non-HDL-bound plasma S1P & $-0.1(-0.7-0.7)$ & $0.2(-0.4-0.9)^{*}$ \\
Fraction of HDL-bound plasma S1P & $1.1(0.3-1.7)$ & $0.8(0.1-5.2)^{*}$ \\
HDL-C normalized HDL-bound plasma S1P [pmol/mg] & $534(308-811)$ & $418(62-1883)$ \\
Non-HDL-bound plasma S1P:HDL-C normalized HDL-bound plasma S1P [mg/mL] & $-0.05(-0.3-0.6)$ & $0.1(-0.5-4.3)^{*}$ \\
Plasma HDL-C [mg/mL] & $0.48(0.27-0.78)$ & $0.42(0.25-0.74)$ \\
\hline
\end{tabular}

Fig. 1. Levels of HDL-bound plasma S1P and HDL-C normalized HDL-bound plasma S1P are negatively associated with the overall CAD severity. Levels of HDL-bound plasma S1P and HDL-C normalized HDLbound plasma S1P were measured in patients with CAD classified according to the burden of coronary atherosclerosis (1-vessel-, multi-vessel (2-vessel- or 3 -vessel)-disease). Circles indicate outliers, asterisks indicate extreme values. For graphical reasons, one value of each parameter of the multi-VD group is not shown (HDL-bound plasma S1P: 1149pmol/ $\mathrm{mL}$, HDL-C normalized HDL-bound plasma S1P: $1883 \mathrm{pmol} / \mathrm{mg}$ ). CAD - coronary artery disease, HDL - high density-lipoproteins, HDL-C - high density-lipoprotein cholesterol, S1P - sphingosine 1-phosphate, VD - vessel disease.

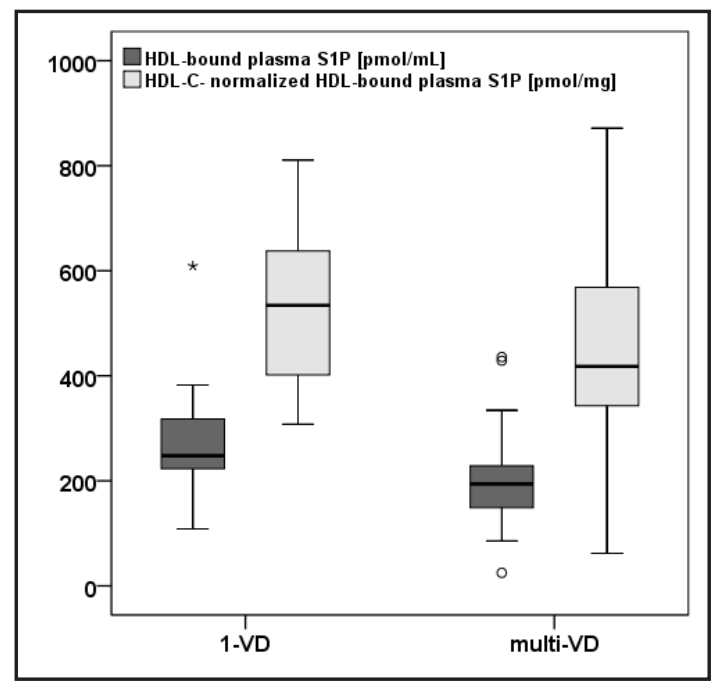

Table 5. ROC analysis of S1P-related parameters in patients with 1-vessel disease or multi-vessel (2-vesselor 3-vessel) -disease. AUC - area under the curve, HDL - high density-lipoproteins, HDL-C - high density-lipoprotein cholesterol, P - P-value, ROC - receiver operating curve, SE - standard error, S1P - sphingosine 1-phosphate, 95\% CI - 95\% confidence interval

\begin{tabular}{lcccc}
\hline & AUC & SE & P & $95 \%$ CI \\
\hline HDL-bound plasma S1P [pmol/mL] & 0.72 & 0.07 & 0.01 & $0.58-0.87$ \\
Non-HDL-bound plasma S1P [pmol/mL] & 0.73 & 0.07 & 0.006 & $0.59-0.87$ \\
Fraction of non-HDL-bound plasma S1P & 0.71 & 0.07 & 0.01 & $0.57-0.86$ \\
Fraction of HDL-bound plasma S1P & 0.71 & 0.07 & 0.01 & $0.57-0.86$ \\
HDL-C normalized HDL-bound plasma S1P [pmol/mg] & 0.64 & 0.08 & 0.11 & $0.49-0.79$ \\
Proportion of non-HDL-bound plasma S1P:HDL-C normalized HDL-bound & 0.72 & 0.07 & 0.01 & $0.58-0.86$ \\
plasma S1P [mg/mL] & & & \\
\hline
\end{tabular}

In addition, multi-VD was associated with a lower fraction of HDL-bound plasma S1P than 1 -VD (0.8 vs. $1.1, \mathrm{P}<0.05)$, but with a higher fraction of non-HDL-bound plasma S1P $(0.2$ vs. -0.1 in $1-V D, P<0.05)$. Furthermore, patients with multi-VD had lower HDL-C normalized HDL-bound plasma S1P than patients with 1-VD (418pmol/mg vs. 534pmol/mg, Fig. 1). Finally, their proportion of non-HDL-bound to HDL-bound plasma S1P was higher $(0.1 \mathrm{mg} /$ $\mathrm{mL}$ vs. $-0.05 \mathrm{mg} / \mathrm{mL}, \mathrm{P}<0.05)$. All parameters are shown in detail in Table 4. 


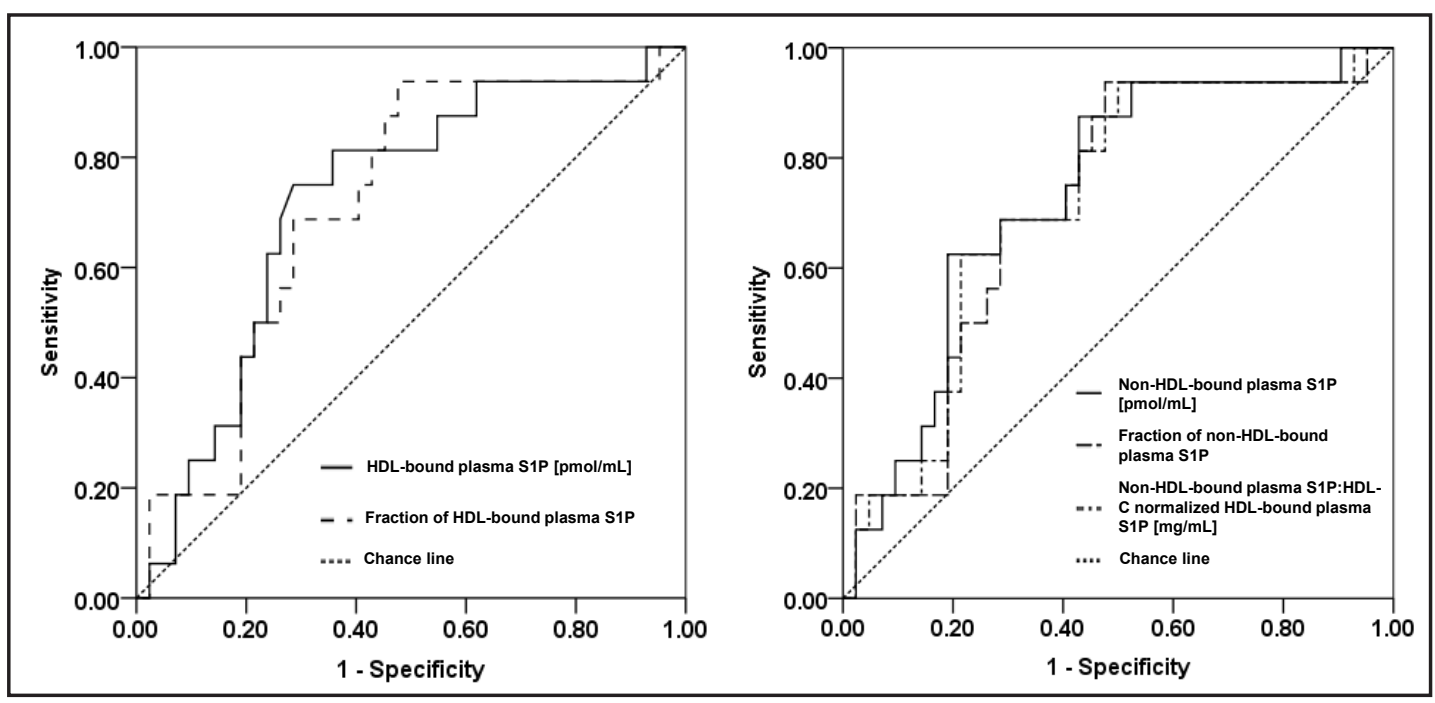

Fig. 2. S1P-related parameters in plasma discriminate patients with 1-vessel-disease from patients with multi-vessel-disease. Patient with CAD were classified according to the burden of coronary atherosclerosis (1-vessel- (limited), multi-vessel (2-vessel- or 3-vessel)-disease). The levels of HDL-bound plasma S1P and the fraction of HDL-bound plasma S1P (left panel) or of non-HDL-bound plasma S1P, the fraction of non-HDL-bound plasma S1P and the proportion of non-HDL-bound plasma S1P to HDL-C normalized HDLbound plasma S1P (right panel) discriminated 1-VD from multi-VD. CAD - coronary artery disease, HDL - high density-lipoproteins, HDL-C - high density-lipoprotein cholesterol, S1P - sphingosine 1-phosphate, VD - vessel disease.

Table 6. Cut-off levels of HDL-bound plasma S1P, non-HDL-bound plasma S1P and the proportion of nonHDL-bound plasma S1P:HDL-C normalized HDL-bound plasma S1P, and odds ratios for multi-vessel (2-vessel- or 3-vessel) -disease. HDL - high density-lipoproteins, HDL-C - high density-lipoprotein cholesterol, P - P-value, S1P - sphingosine 1-phosphate, VD - vessel disease, 95\% CI - 95\% confidence interval. Cut-off levels were defined by Youden index in the ROC analysis tables. * Odds ratio for having multi-vessel (2-vessel- or 3-vessel) -disease if levels of the respective parameters were above the cut-off value

\begin{tabular}{|c|c|c|c|c|c|c|c|}
\hline & Cut-off value & $\begin{array}{c}\text { Percentage of } \\
\text { patients with 1-VD } \\
\text { and parameter } \\
\text { above the cut-off } \\
\text { level }\end{array}$ & $\begin{array}{l}\text { Percentage of } \\
\text { patients with } \\
\text { multi-VD and } \\
\text { parameter } \\
\text { above the cut- } \\
\text { off level }\end{array}$ & $\begin{array}{l}\text { P of the cross- } \\
\text { tables of the } \\
\text { dichotomized cut- } \\
\text { off values }\end{array}$ & $\begin{array}{c}\text { Odds ratio for } \\
\text { having multi-VD }\end{array}$ & $95 \% \mathrm{CI}$ & $P$ \\
\hline HDL-bound plasma S1P [pmol/mL] & 226 & 75 & 29 & $<0.01$ & 0.13 & $0.04-0.5$ & $<0.01$ \\
\hline Non-HDL-bound plasma S1P $[\mathrm{pmol} / \mathrm{mL}]$ & 32 & 13 & 57 & $<0.01$ & 9.3 & $1.9-46.4$ & $<0.01$ \\
\hline Fraction of non-HDL-bound plasma S1P & 0.15 & 6 & 52 & $<0.01$ & 16.5 & $2.0-136.5$ & $<0.01$ \\
\hline Fraction of HDL-bound plasma S1P & 0.85 & 94 & 48 & $<0.01$ & 0.06 & $0.01-0.50$ & $<0.01$ \\
\hline $\begin{array}{l}\text { Proportion of non-HDL-bound plasma S1P:HDL-C } \\
\text { normalized HDL-bound plasma S1P [mg/mL] }\end{array}$ & 0.10 & 6 & 50 & $<0.01$ & 15.0 & $1.81-124.1$ & $<0.05$ \\
\hline
\end{tabular}

HDL-bound plasma S1P discriminates patients with 1-vessel-disease from patients with multi-vessel-disease

We then tested whether the S1P-related parameters identified above could discriminate patient groups according to disease severity.

In the ROC analysis, both HDL-bound and non-HDL-bound plasma S1P discriminated patients with 1-VD from those with multi-VD (Fig. 2 and Table 5). More patients with 1-VD than multi-VD had HDL-bound plasma S1P levels higher than the cut-off value of 226pmol/ $\mathrm{mL}$, or levels of non-HDL-bound plasma S1P below the cut-off value of 32pmol/mL (Table 6). Thus, the odds ratio for having multi-VD was 0.13 when HDL-bound plasma S1P was above the cut-off level and 9.33 when non-HDL-bound plasma S1P was above the cut-off level (Table 6). 
Table 7. Correlations of the levels of the different S1P-related parameters of the first visit with the levels of the follow up visit. HDL - high density-lipoproteins, HDL-C - high density-lipoprotein cholesterol, S1P sphingosine 1-phosphate. The correlation coefficients for each pair of variables "levels at first visit - levels at follow up visit" are shown. * $\mathrm{P}<0.01$

\begin{tabular}{lc}
\hline & $\begin{array}{c}\text { Coefficient of the correlation } \\
\text { "first visit - follow up visit" }\end{array}$ \\
\hline S1P in HDL/cholesterol in HDL [pmol/mg] & $0.47^{*}$ \\
Total plasma S1P [pmol/mL] & 0.15 \\
Non-HDL-bound plasma S1P [pmol/mL] & $0.35^{*}$ \\
Fraction of non-HDL-bound plasma S1P & 0.30 \\
Fraction of HDL-bound plasma S1P & 0.30 \\
Non-HDL-bound plasma S1P:HDL-C normalized HDL-bound plasma S1P [mg/mL] & $0.36^{*}$ \\
\hline
\end{tabular}

In addition, the fractions of both HDL-bound and non-HDL-bound plasma S1P discriminated patients with 1-VD from those with multi-VD in the ROC analysis (Fig. 2 and Table 5). More patients with 1-VD than with multi-VD had the fraction of HDL-bound plasma S1P levels higher than the cut-off value of $0.85 \mathrm{pmol} / \mathrm{mL}$ ( $94 \%$ vs. $48 \%$, Table 6 ), but levels of the fraction of non-HDL-bound plasma S1P below the cut-off value of $0.15 \mathrm{pmol} / \mathrm{mL}(6 \%$ vs. $52 \%$, Table 6). The odds ratio for having multi-VD was 0.06 when the fraction of HDLbound plasma S1P was above the cut-off level, but 16.5 when the fraction of non-HDL-bound plasma S1P was above the cut-off level (Table 6).

Finally, the proportion of non HDL-bound to HDL-C normalized HDL-bound plasma S1P was discriminative for 1-VD from multi-VD as well (Fig. 2 and Table 5). Patients with 1-VD were less likely $(6 \%)$ to have levels higher than the cut-off value of $0.1 \mathrm{mg} / \mathrm{mL}$ than patients with multi-VD (50\%, Table 6). Thus, the odds ratio for having multi-VD was 15.0 when the proportion of non-HDL-bound to HDL-C normalized HDL-bound plasma S1P was above the cut off-value (Table 6).

\section{Patient group of the follow up visit}

In 48 patients of the 59 study patients (81\%) an angiography was performed within the following 6 months (1-18months) for various reasons ("follow up visit"). Results of S1P measurements in HDL and in plasma could be obtained of 32 patients of this group (54\% of the initial study population; Table 2). Using the follow up angiograms, $52(78 \%)$ of the initially treated lesions were analyzed by QCA again (Table 3).

\section{S1P-related parameters at first visit and at follow up are closely associated}

Total plasma S1P and HDL-C levels were similar on first and follow up visit. None of the other parameters delineated above had changed at follow up with one remarkable exception: The fraction of HDL-bound plasma S1P was decreased and that of non-HDL-bound plasma S1P was increased at follow up (Table 2). Similar to the first visit, plasma HDL-C closely correlated with HDL-bound plasma S1P $(\mathrm{r}=0.69, \mathrm{P}<0.01)$, but this time, it also correlated with total plasma S1P $(\mathrm{r}=0.4, \mathrm{P}=0.04)$. As at the first visit, the S1P content in isolated HDL (153pmol/mg protein) was positively correlated to total plasma S1P levels $(\mathrm{r}=0.48, \mathrm{P}<0.01)$ and negatively to non-HDL-bound S1P $(r=-0.39, \mathrm{P}=0.03)$.

Furthermore, the following parameters correlated between first visit and follow up: HDL-bound plasma S1P, non-HDL-bound plasma S1P, HDL-C normalized HDL-bound plasma S1P and the proportion of non-HDL-bound plasma S1P:HDL-C normalized HDL-bound plasma S1P. This may be due to the strong positive correlation of plasma HDL-C between first and follow up visit $(\mathrm{r}=0.80, \mathrm{P}<0.01)$. The detailed results are presented in Table 7 and Fig. 3. 


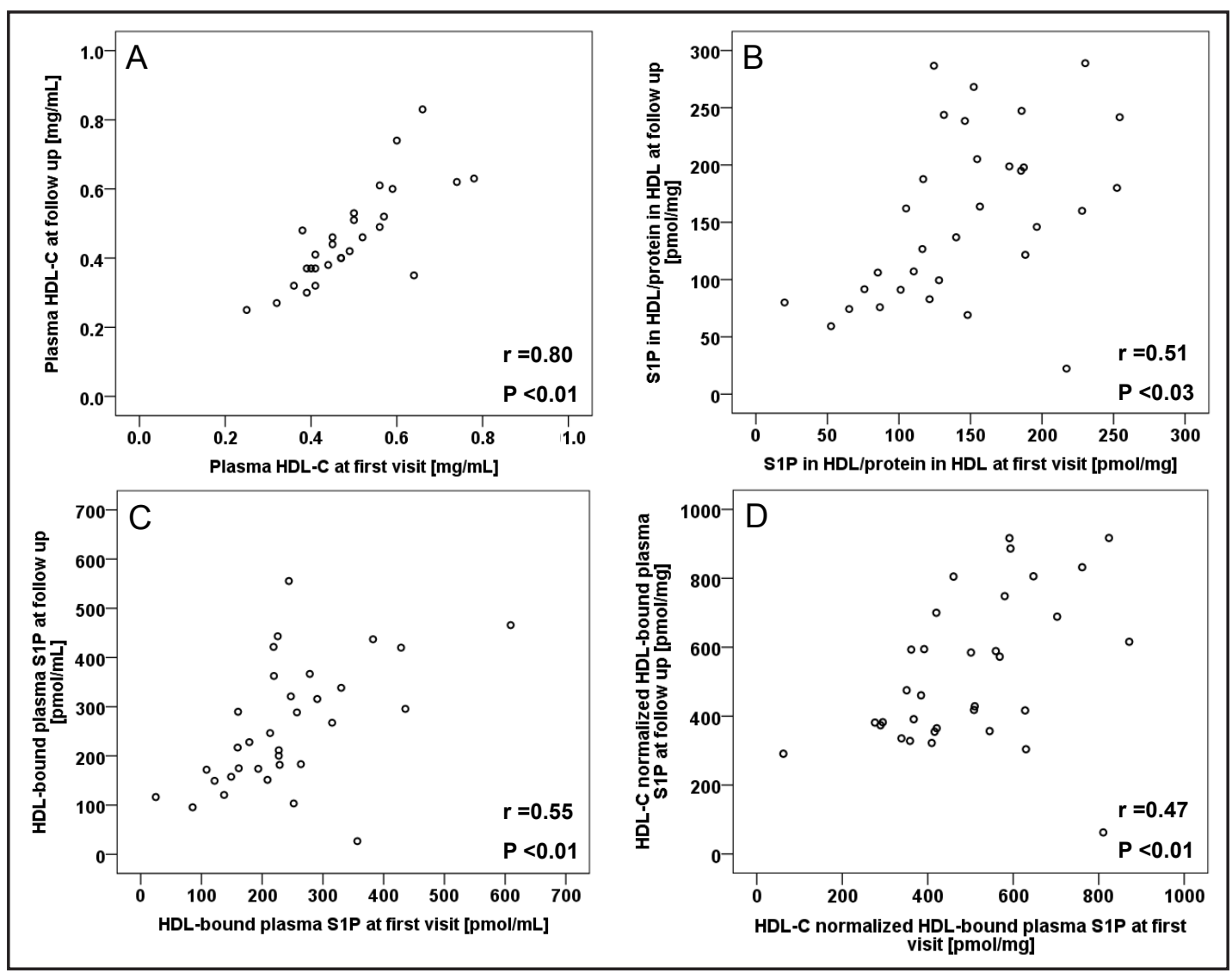

Fig. 3. Levels of HDL-C, S1P content of HDL and HDL-based S1P-related parameters at first visit are positively correlated with the respective levels at follow up. Plasma HDL-C, S1P content of HDL per protein content of HDL, HDL-bound plasma S1P and HDL-C normalized HDL-bound plasma S1P were determined during the first visit and the follow up visit. Spearman's rank-order correlation was used to test for an association of first visit and follow up levels for each variable. The scatter plots show the variable pairs of A) plasma HDL-C, B) S1P content in HDL per mg of protein, D) HDL-bound plasma S1P, and E) HDL-C normalized HDL-bound plasma S1P. HDL - high density-lipoproteins, HDL-C - high density-lipoprotein cholesterol, $\mathrm{P}$ - P-value, $\mathrm{r}$ - correlation coefficient $\mathrm{r}$, S1P - sphingosine 1-phosphate.

S1P-related parameters are not associated with the development of angiographic restenosis

The QCA analysis of the target lesions on the follow up angiograms revealed a very modest degree of restenosis due to the exclusive use of drug-eluting stents (lumen loss of $0.32 \mathrm{~mm}$ and a percent diameter of restenosis of 3.89\%). Only one lesion had a restenosis $>50 \%$, and the binary restenosis rate was $1.5 \%$. The results of the QCA of the target lesion at follow up are presented in detail in Table 3. None of the S1P parameters at the time of enrolment were associated with lumen loss, percent restenosis or any other QCA results at follow up.

\section{Discussion}

Plasma HDL-C levels are epidemiologically negative predictors of coronary artery atherosclerosis $[2,3]$. Therapeutic short-term administration of reconstituted HDL in patients with acute coronary syndromes resulted in coronary plaque stabilization or even regression $[16,17]$. Currently, there are studies under way to test for effects of reconstituted HDL on 
plaque development in stable patients [18]. However, it is not the level of plasma HDL-C alone that is protective against atherosclerosis. The metabolic changes in atherosclerosis are known to alter several important HDL functions, which has led to the definition of a functionally impaired or "dysfunctional" HDL particle [19]. There is clear evidence that HDL functionality is of major importance for its atheroprotective effects [20]. Among other constituents, S1P has been shown to be an important mediator of several potentially antiatherogenic properties of HDL (reviewed in [21]).

In the current study we demonstrate for the first time that plasma S1P bound to HDL but not total plasma S1P per se is negatively associated with the overall severity of CAD and thus constitutes a predictive marker for disease burden. A previous study has shown an association of serum S1P with the extent of coronary obstruction [13] but two important differences to our study should be noted: i) we classified CAD severity by 1-vessel-disease compared to multi-vessel disease (2-vessel- or 3-vessel-disease as routinely used in the clinic), while Deutschman et al. used an arbitrarily set 'coronary score', and ii) we measured plasma S1P instead of serum S1P as platelet activation leads to S1P release and may be a confounding factor. In the present study, we included a cohort of patients with demographic and risk factors typical for patients with stable CAD. Levels of S1P in plasma (both total and bound to HDL or other carriers) were comparable to another population of CAD patients studied earlier by us [12]. As demonstrated before in patients with stable CAD [12], S1P in plasma was bound mainly to HDL also in a population with clinically symptomatic atherosclerosis as studied here.

Our data show that HDL-bound plasma S1P allowed the discrimination of limited disease extent from more severe extent of coronary plaque burden. One interpretation might be that at least the amounts of plasma S1P that are bound to HDL found in this study as cut-off values to discriminate 1-VD from multi-VD are the necessary amount to prevent "spreading" of atherosclerosis. It would be extremely interesting to compare these values in a control group consisting of patients with risk factors for CAD but without manifest atherosclerosis with a group with 1-VD to evaluate whether they might not only prevent "spreading", but altogether the development of atherosclerosis. We did not observe any association of plasma S1P levels with cardiac troponin I after PCI as described by others [15], excluding cardiac ischemia inflicted by PCI as a confounding factor.

The second major finding of our study was that neither HDL-bound plasma S1P nor any of the other S1P-related parameters were associated with the size of the individual lesion that required intervention (with lumen narrowing on QCA being the surrogate marker for the extent of the targeted plaque). QCA analysis measures the lumen dimensions of a vessel in absolute values and relative to a "healthy" reference segment of the vessel, but does not allow the calculation of the actual plaques volume or composition. Specifically the plaque composition would be of true interest in regard to possible protective effects of HDL-bound S1P considering the experimentally proven plaque stabilizing properties of HDL mimetics [22] or apolipoprotein $\mathrm{AI}_{\text {Milano }}$-based HDL-like lipoproteins [23-25]. Another relevant point is that the mechanisms leading to clinical symptoms of ischemia in stable CAD - and attributed angiographically to a distinct coronary plaque subsequently treated by PCI - are rather multi-facetted [26]. Thus the PCI treatment of a lesion identified as a culprit for symptoms in stable CAD is not directly related to acute ongoing plaque growth or composition. Therefore, the association of HDL-bound plasma S1P with disease burden rather than with individual stenosis might be the more significant one and could define a novel marker for "general plaque burden".

The third major observation of our study was the remarkable stability of all measured S1P-related parameters including HDL-bound plasma S1P over the follow up period for 6 months. All parameters correlated closely between first visit and follow up after PCI. This and the lack of any relationship to the degree of restenosis argue against a linear relationship of S1P or its carriers on plaque development. The importance of HDL as the main binding partner of S1P in plasma was demonstrated by the correlation of plasma HDL-C with HDLbound plasma S1P at first visit and follow up. The negative correlation of S1P within isolated 
HDL (expressed as pmol per mg protein or cholesterol) to non-HDL-bound plasma S1P also suggests that HDL may be "actively" acquiring S1P. There was a strong correlation of plasma HDL-C levels at first visit and follow up, and a clear correlation of HDL-bound plasma S1P with HDL-C. Altogether, these results demonstrate that high plasma HDL-C as a surrogate for HDL particle number is important to achieve high levels of HDL-bound plasma S1P. This is the first study presenting follow up data of the distribution of S1P in plasma in patients with stable CAD. There is so far only one other study addressing this [27], but it looked at patients with myocardial infarction and plasma S1P levels only.

\section{Limitations}

This is a retrospective, observational study that has, therefore, several limitations. The findings were derived from a well defined cohort of patients and may not hold for other populations with different characteristics. As $90 \%$ of the patients had CAD already known prior to PCI, the time of plaque development at the site of intervention was unknown. Therefore, the results do not allow any conclusions in respect to patients with newly diagnosed or newly developing CAD. The extent of the CAD was defined by the operator performing the PCI procedure but was not based on standardized procedures. However, the operator was blinded to the patients' participation in the study and the biochemical results and decided by angiogram and patient's history only. We have studied the development of in-stent-restenosis instead of plaque development in native vessels, as the latter is not feasible in a study involving human subjects. In the restenosis part of the study, we observed a very low restenosis rate (diameter of restenosis 3.89\%, binary restenosis rate $1.5 \%$ ). This is not surprising, considering that the majority of lesions had been treated with drug eluting stents, and that the patients had received optimal medical therapy after the procedure (although it complies well with published results [14]). However, patients were asked to participate in the study prior to intervention so that the type of stent implanted was not known beforehand. Finally, intravascular ultrasound or virtual histology might have allowed to associate S1P-related parameters with plaque characteristics, but were unfortunately not available in the majority of the cases. Altogether this study includes a typical population of patients with stable coronary artery disease treated according to clinical standards and therefore represents "real life" conditions.

\section{Acknowledgements}

This study was supported by the Schwerpunktprogramm: Sphingolipids - Signal and Disease (SPP 1267) of the Deutsche Forschungsgemeinschaft, Project LE 940/4-2.

\section{Disclosure Statement}

The authors have no sponsorship or funding arrangements relating to this research nor any conflicts of interest to declare.

\section{References}

1 Lozano R, Naghavi M, Foreman K, Lim S, Shibuya K, Aboyans V, Abraham J, Adair T, Aggarwal R, Ahn SY, Alvarado M, Anderson HR, Anderson LM, Andrews KG, Atkinson C, Baddour LM, Barker-Collo S, Bartels DH, Bell ML, Benjamin EJ, Bennett D, Bhalla K, Bikbov B, Bin Abdulhak A, Birbeck G, Blyth F, Bolliger I, Boufous S, Bucello C, Burch M, Burney P, Carapetis J, Chen H, Chou D, Chugh SS, Coffeng LE, Colan SD, Colquhoun S, Colson KE, Condon J, Connor MD, Cooper LT, Corriere M, Cortinovis M, de Vaccaro KC, Couser W, Cowie BC, Criqui MH, Cross M, Dabhadkar KC, Dahodwala N, De Leo D, Degenhardt L, Delossantos A, Denenberg 


\begin{tabular}{|c|c|c|}
\hline Cellular Physiology & Cell Physiol Biochem 2014;34:172-184 & \\
\hline and Biochemistry & $\begin{array}{l}\text { DOI: 10.1159/000362993 } \\
\text { Published online: June 16, } 2014\end{array}$ & $\begin{array}{l}\text { O } 2014 \text { S. Karger AG, Basel } \\
\text { www.karger.com/cpb }\end{array}$ \\
\hline
\end{tabular}

J, Des Jarlais DC, Dharmaratne SD, Dorsey ER, Driscoll T, Duber H, Ebel B, Erwin PJ, Espindola P, Ezzati M, Feigin V, Flaxman AD, Forouzanfar MH, Fowkes FG, Franklin R, Fransen M, Freeman MK, Gabriel SE, Gakidou E, Gaspari F, Gillum RF, Gonzalez-Medina D, Halasa YA, Haring D, Harrison JE, Havmoeller R, Hay RJ, Hoen B, Hotez PJ, Hoy D, Jacobsen KH, James SL, Jasrasaria R, Jayaraman S, Johns N, Karthikeyan G, Kassebaum N, Keren A, Khoo JP, Knowlton LM, Kobusingye O, Koranteng A, Krishnamurthi R, Lipnick M, Lipshultz SE, Ohno SL, Mabweijano J, MacIntyre MF, Mallinger L, March L, Marks GB, Marks R, Matsumori A, Matzopoulos R, Mayosi BM, McAnulty JH, McDermott MM, McGrath J, Mensah GA, Merriman TR, Michaud C, Miller M, Miller TR, Mock C, Mocumbi AO, Mokdad AA, Moran A, Mulholland K, Nair MN, Naldi L, Narayan KM, Nasseri K, Norman P, O'Donnell M, Omer SB, Ortblad K, Osborne R, Ozgediz D, Pahari B, Pandian JD, Rivero AP, Padilla RP, Perez-Ruiz F, Perico N, Phillips D, Pierce K, Pope CA, 3rd, Porrini E, Pourmalek F, Raju M, Ranganathan D, Rehm JT, Rein DB, Remuzzi G, Rivara FP, Roberts T, De Leon FR, Rosenfeld LC, Rushton L, Sacco RL, Salomon JA, Sampson U, Sanman E, Schwebel DC, Segui-Gomez M, Shepard DS, Singh D, Singleton J, Sliwa K, Smith E, Steer A, Taylor JA, Thomas B, Tleyjeh IM, Towbin JA, Truelsen T, Undurraga EA, Venketasubramanian N, Vijayakumar L, Vos T, Wagner GR, Wang M, Wang W, Watt K, Weinstock MA, Weintraub R, Wilkinson JD, Woolf AD, Wulf S, Yeh PH, Yip P, Zabetian A, Zheng ZJ, Lopez AD, Murray CJ, AlMazroa MA, Memish ZA: Global and regional mortality from 235 causes of death for 20 age groups in 1990 and 2010: a systematic analysis for the Global Burden of Disease Study 2010. Lancet 2012;380:20952128.

2 Gordon T, Castelli WP, Hjortland MC, Kannel WB, Dawber TR: High density lipoprotein as a protective factor against coronary heart disease. The Framingham Study. Am J Med 1977;62:707-714.

-3 Rahilly-Tierney C, Sesso HD, Michael Gaziano J, Djousse L: High-density lipoprotein and mortality before age 90 in male physicians. Circ Cardiovasc Qual Outcomes 2012;5:381-386.

4 Assmann G, Gotto AM Jr: HDL cholesterol and protective factors in atherosclerosis. Circulation 2004;109:SIII8-14.

-5 Besler C, Luscher TF, Landmesser U: Molecular mechanisms of vascular effects of High-density lipoprotein: alterations in cardiovascular disease. EMBO Mol Med 2012;4:251-268.

-6 Theilmeier G, Schmidt C, Herrmann J, Keul P, Schafers M, Herrgott I, Mersmann J, Larmann J, Hermann S, Stypmann J, Schober O, Hildebrand R, Schulz R, Heusch G, Haude M, von Wnuck Lipinski K, Herzog C, Schmitz M, Erbel R, Chun J, Levkau B: High-density lipoproteins and their constituent, sphingosine1-phosphate, directly protect the heart against ischemia/reperfusion injury in vivo via the S1P3 lysophospholipid receptor. Circulation 2006;114:1403-1409.

-7 Nofer JR, van der Giet M, Tolle M, Wolinska I, von Wnuck Lipinski K, Baba HA, Tietge UJ, Godecke A, Ishii I, Kleuser B, Schafers M, Fobker M, Zidek W, Assmann G, Chun J, Levkau B: HDL induces NO-dependent vasorelaxation via the lysophospholipid receptor S1P3. J Clin Invest 2004;113:569-581.

-8 Kimura T, Sato K, Kuwabara A, Tomura H, Ishiwara M, Kobayashi I, Ui M, Okajima F: Sphingosine 1-phosphate may be a major component of plasma lipoproteins responsible for the cytoprotective actions in human umbilical vein endothelial cells. J Biol Chem 2001;276:31780-31785.

-9 Argraves KM, Gazzolo PJ, Groh EM, Wilkerson BA, Matsuura BS, Twal WO, Hammad SM, Argraves WS: High density lipoprotein-associated sphingosine 1-phosphate promotes endothelial barrier function. J Biol Chem 2008;283:25074-25081.

10 Tolle M, Pawlak A, Schuchardt M, Kawamura A, Tietge UJ, Lorkowski S, Keul P, Assmann G, Chun J, Levkau B, van der Giet M, Nofer JR: HDL-associated lysosphingolipids inhibit NAD(P)H oxidase-dependent monocyte chemoattractant protein-1 production. Arterioscler Thromb Vasc Biol 2008;28:1542-1548.

-11 Gonzalez-Diez M, Rodriguez C, Badimon L, Martinez-Gonzalez J: Prostacyclin induction by high-density lipoprotein (HDL) in vascular smooth muscle cells depends on sphingosine 1-phosphate receptors: effect of simvastatin. Thromb Haemost 2008;100:119-126.

-12 Sattler KJ, Elbasan S, Keul P, Elter-Schulz M, Bode C, Graler MH, Brocker-Preuss M, Budde T, Erbel R, Heusch G, Levkau B: Sphingosine 1-phosphate levels in plasma and HDL are altered in coronary artery disease. Basic Res Cardiol 2010;105:821-832.

13 Deutschman DH, Carstens JS, Klepper RL, Smith WS, Page MT, Young TR, Gleason LA, Nakajima N, Sabbadini RA: Predicting obstructive coronary artery disease with serum sphingosine-1-phosphate. Am Heart J 2003;146:62-68. 


\section{Cellular Physiology Cell Physiol Biochem 2014;34:172-184 \begin{tabular}{l|l} 
Dol: 10.1159/000362993 2014 & 2014 S. Karger AG, Basel
\end{tabular} www.karger.com/cpb \\ Sattler et al.: HDL-S1P Predicts Plaque Burden}

14 Mauri L, Orav EJ, Kuntz RE: Late loss in lumen diameter and binary restenosis for drug-eluting stent comparison. Circulation 2005;111:3435-3442.

-15 Egom EE, Mamas MA, Chacko S, Stringer SE, Charlton-Menys V, El-Omar M, Chirico D, Clarke B, Neyses L, Cruickshank JK, Lei M, Fath-Ordoubadi F: Serum sphingolipids level as a novel potential marker for early detection of human myocardial ischaemic injury. Front Physiol 2013;4:130.

-16 Nicholls SJ, Tuzcu EM, Sipahi I, Schoenhagen P, Crowe T, Kapadia S, Nissen SE: Relationship between atheroma regression and change in lumen size after infusion of apolipoprotein A-I Milano. J Am Coll Cardiol 2006;47:992-997.

-17 Tardif JC, Gregoire J, L'Allier PL, Ibrahim R, Lesperance J, Heinonen TM, Kouz S, Berry C, Basser R, Lavoie MA, Guertin MC, Rodes-Cabau J: Effects of reconstituted high-density lipoprotein infusions on coronary atherosclerosis: a randomized controlled trial. JAMA 2007;297:1675-1682.

18 Krause BR, Remaley AT: Reconstituted HDL for the acute treatment of acute coronary syndrome. Curr Opin Lipidol 2013;24:480-486.

19 Kontush A, Chapman MJ: Functionally defective high-density lipoprotein: a new therapeutic target at the crossroads of dyslipidemia, inflammation, and atherosclerosis. Pharmacol Rev 2006;58:342-374.

20 Feig JE, Hewing B, Smith JD, Hazen SL, Fisher EA: High-density lipoprotein and atherosclerosis regression: evidence from preclinical and clinical studies. Circ Res 2014;114:205-213.

21 Sattler K, Levkau B: Sphingosine-1-phosphate as a mediator of high-density lipoprotein effects in cardiovascular protection. Cardiovasc Res 2009;82:201-211.

-22 Tardy C, Goffinet M, Boubekeur N, Ackermann R, Sy G, Bluteau A, Cholez G, Keyserling C, Lalwani N, Paolini JF, Dasseux JL, Barbaras R, Baron R: CER-001, a HDL-mimetic, stimulates the reverse lipid transport and atherosclerosis regression in high cholesterol diet-fed LDL-receptor deficient mice. Atherosclerosis 2014;232:110-118.

-23 Shah PK, Yano J, Reyes O, Chyu KY, Kaul S, Bisgaier CL, Drake S, Cercek B: High-dose recombinant apolipoprotein A-I(milano) mobilizes tissue cholesterol and rapidly reduces plaque lipid and macrophage content in apolipoprotein e-deficient mice. Potential implications for acute plaque stabilization. Circulation 2001;103:3047-3050.

24 Shah PK, Nilsson J, Kaul S, Fishbein MC, Ageland H, Hamsten A, Johansson J, Karpe F, Cercek B: Effects of recombinant apolipoprotein A-I(Milano) on aortic atherosclerosis in apolipoprotein E-deficient mice. Circulation 1998;97:780-785.

25 Chiesa G, Monteggia E, Marchesi M, Lorenzon P, Laucello M, Lorusso V, Di Mario C, Karvouni E, Newton RS, Bisgaier CL, Franceschini G, Sirtori CR: Recombinant apolipoprotein A-I(Milano) infusion into rabbit carotid artery rapidly removes lipid from fatty streaks. Circ Res 2002;90:974-980.

26 Kones R: Recent advances in the management of chronic stable angina I: approach to the patient, diagnosis, pathophysiology, risk stratification, and gender disparities. Vasc Health Risk Manag 2010;6:635-656.

27 Knapp M, Lisowska A, Zabielski P, Musial W, Baranowski M: Sustained decrease in plasma sphingosine-1phosphate concentration and its accumulation in blood cells in acute myocardial infarction. Prostaglandins Other Lipid Mediat 2013;106:53-61. 